\title{
The effect of reliability consideration on the application of quality index
}

\author{
H. Seifoddini ${ }^{\mathrm{a}} \quad$ M. Djassemi ${ }^{\mathrm{b}}$ \\ ${ }^{\mathrm{a}}$ Industrial and Manufacturing Engineering Department, The University of Wisconsin-Milwaukee, P.O. Box 784, EMS \\ Building, Milwaukee, WI, USA \\ ${ }^{\mathrm{b}}$ Department of Industrial Studies, The University of Wisconsin-Platteville, USA
}

\begin{abstract}
Quality index (QI) has been proposed as a screening mechanism for machine-part matrices in the development of cellular manufacturing systems. In this paper the effect of reliability consideration on the application of QI and the relative sensitivity of job shop and cellular manufacturing systems to reliability changes are evaluated by simulation modeling. Performance measures such as mean flow time and work-in-process inventories are used in the comparative study of job shop and cellular manufacturing.
\end{abstract}

Keywords: Reliability consideration; Quality index; Cellular manufacturing

\section{Introduction}

Cellular manufacturing is now widely accepted as an effective configuration for batch-type manufacturing systems. It improves the manufacturing efficiency by organizing production into independent manufacturing units called "machine cells". A machine cell in cellular manufacturing has the capability of fully processing a family of similar parts (part-family). The reduction in set up times, simplification of material flow, and shortening of throughput times are some of the improvement offered by cellular manufacturing (Burbidge 1992; Hyer 1984).

A cellular manufacturing system is, usually, developed based on the machining requirements of parts which are organized in a binary matrix with zero/one entries (machine-part matrix). A block diagonal form of a machine-part matrix in which "one" entries are concentrated along the diagonal of the matrix is used to identify machine-component groups for cellular manufacturing (King \& Nakornchai, 1982; McAuley, 1972). The structure of a machine-part matrix has a significant impact on the performance of a cellular manufacturing system. 
Despite significant changes brought about by the introduction of cellular manufacturing, the controversy about the performance of cellular manufacturing systems remains unresolved to date. A frequently cited problem in this respect is the excessive inventories due to the dedication of machines to machine cells (Christy \& Udayan, 1986; Flynn \& Jacobs, 1986). In response to this criticism of cellular manufacturing systems, several studies have been conducted that consider the initial structure of the machinepart matrix and its impact on the performance of such systems (Djassemi, 1994; Seifoddini \& Djassemi, 1995). These studies show that the failure of a cellular manufacturing system in most cases can be traced back to the characteristics of the original manufacturing system. Some of the most influential factors in the performance of cellular manufacturing systems include the structure of the machine-part matrix, the stability of the product mix of the manufacturing system, and the reliability of machines in manufacturing cells.

Quantitative measures such as bond energy (McCormick, Schweitzer \& White, 1972), grouping efficiency (Chandrasekharan \& Rajagopalan, 1989), grouping efficacy (Kumar \& Chandrasekharan, 1990), grouping capability index (Hsu, 1990), and quality index (QI) (Seifoddini \& Djassemi, 1997) have been developed to evaluate the structure of the machine-part matrix. QI has been specifically developed to determine the suitability of a manufacturing system based on the structure of the machine-part matrix, the production volume of parts in the product mix, and the processing times of manufacturing operations. A simulation study by Seifoddini and Djassemi (1995) established the relationship between the values of QI and the performance of the corresponding cellular manufacturing system. This study indicates that low value of QI for the block diagonal form of the machine-part matrix is a warning signal for possible failure of the associated cellular manufacturing system, in terms of, its performance as compared to the corresponding job shop manufacturing system. On the other hand, a high value of QI is, generally, an indication of superior performance by the cellular manufacturing system. Therefore, QI, can be used as a preliminary screening mechanism for the selection of a manufacturing system for conversion to cellular manufacturing.

As mentioned earlier, the reliability of machines is an influential factor in the performance of a cellular manufacturing system. It is expected that both the QI value for the selection of a manufacturing system for cellular manufacturing and the performance of such a system is affected by the reliability level of manufacturing facilities. Previous studies of QI and its relation to the performance of cellular manufacturing systems have not considered the reliability factor.

In this paper, the performance of a manufacturing system under job shop and cellular manufacturing is evaluated at different QI levels subject to changes in the reliability of machines in manufacturing cells.

\section{Definition of the problem}

Reliability is one of the major factors affecting the performance of a manufacturing system. Not only delays due to the machine breakdowns impact the production rate, but the disturbances caused by these breakdowns lead to scheduling problems which decrease the productivity of the entire manufacturing operations. Due to the varying nature of production systems, the adverse effects of machine break downs are felt differently in different manufacturing situations. While, highly automated mass production systems are most sensitive to the reliability changes, job shop manufacturing systems are more flexible in dealing with machine failures (Flynn, 1989; Madu \& Kuei, 1992; Miriyala \& Viswandham, 1989).

Dedication of machines and part-families to manufacturing cells in cellular manufacturing while 


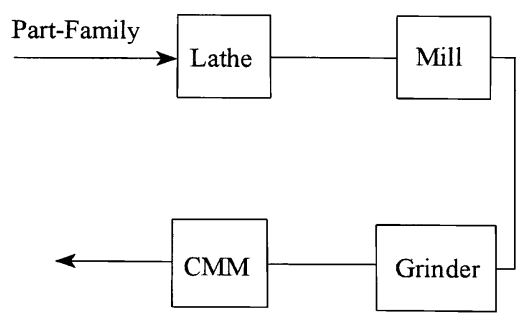

Fig. 1. Series reliability configuration in cellular manufacturing.

providing the opportunity for setup reductions, decreases the scheduling flexibility, especially, in the case of machine break down. This is so because in functional layouts the proximity of identical machines makes rerouting of parts in the cases of machine failure an easy exercise. The same task in cellular manufacturing leads to intercellular transportation which goes against the very foundation of independent machine cells. Consequently, it is natural to believe that reliability changes, have a more profound impact on cellular manufacturing systems than on job shop manufacturing systems.

Generally, the reliability model for a cellular manufacturing systems is close to series reliability configuration (Fig. 1). The reliability model for machines in a job shop manufacturing system can be more closely represented by parallel configuration (Fig. 2). This is true because in a job shop system machines of the same type are in one location and when one fails the part can be easily routed to an identical machine. The rerouting in cellular manufacturing system may require transfer of the part of another machine cell.

As can be interpreted from these two types of reliability models, for the same system reliability level, a cellular manufacturing system demands a much higher reliability for individual machines (Kapur \& Lamberson, 1986).

While, these two simple reliability models in Figs. 1 and 2 explain the underlying differences between cellular manufacturing and job shop, by no means they reflect the complexity of reliability functions in a real manufacturing system. The reliability analysis of cellular and job shop manufacturing systems can be more realistically dealt with by using simulation modeling (Law \& Kelton, 1991). To compare the performance of a job shop and cellular manufacturing system, subject to machine breakdown, a single machine-part matrix under job shop and cellular manufacturing configurations will be employed. As a result, production factors such as machines, parts, production volume, processing times and so on in the two systems are identical. Consequently, the main difference between the two systems is the organization of production which affects production scheduling, materials handling, manpower assignment and so on.

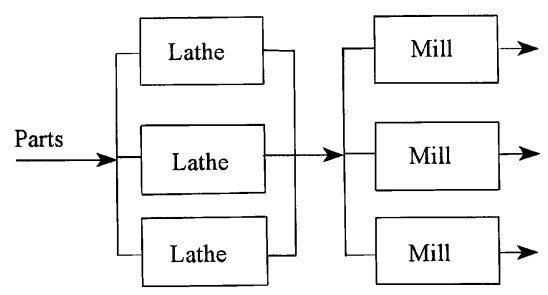

Fig. 2. Parallel reliability configuration in job shop manufacturing. 
The reliability of a manufacturing system as a function of its components (machine reliability) is also dependent upon manufacturing system configuration as discussed earlier. By using a single machine part-matrix with a stable production volume in the comparative study of job shop and cellular manufacturing systems, the source of change will be limited to the difference between the reliability of the two systems. The system reliability, for most part, depends upon machine reliability and manufacturing system configuration. Both of which will be used as the main parameters of the simulation model and will be input as values for different machine reliability levels and QI, respectively.

QI has been developed to evaluate the suitability of a manufacturing system for conversion to cellular manufacturing. It is based on the data in the machine-part matrix, production volume of parts in the product mix, and processing times of manufacturing operations. QI is defined as follows:

$$
\begin{aligned}
& \mathrm{QI}=1-\frac{\mathrm{ICW}}{\mathrm{PW}} \\
& \mathrm{ICW}=\sum_{c=1}^{C} \sum_{m=1}^{M}\left[Y_{m c}\left(\sum_{p=1}^{P}\left(1-Z_{p c}\right) X_{m p} V_{p} T_{m p}\right)\right]
\end{aligned}
$$

where ICW is the total plant's intercellular workload in time units

$$
\begin{aligned}
& Y_{m c}: \begin{cases}1 & \text { If machine } \mathrm{m} \text { is assigned to cell } c \\
0 & \text { Otherwise }\end{cases} \\
& Z_{p c}: \begin{cases}1 & \text { If part } c \text { is assigned to cell } c \\
0 & \text { Otherwise }\end{cases} \\
& X_{m p}: \begin{cases}1 & \text { If part } p \text { has operation on machine } m \\
0 & \text { Otherwise }\end{cases}
\end{aligned}
$$

where $V_{p}$ is the volume of part $p, T_{m p}$ is processing time of part $p$ on machine $m, M$ the total number of machines, $P$ the total number of parts and $C$ the total number of cells

$$
\mathrm{PW}=\sum_{m=1}^{M} \sum_{p=1}^{P} X_{m p} V_{p} T_{m p}
$$

where PW is the total workload of plant in unit time and $X_{m p}, V_{p}$ and $T_{m p}$ as defined before.

High values of QI represent manufacturing systems which when are converted to cellular manufacturing systems have low dependency among their machine cells. Such cellular manufacturing systems are more likely to out perform the corresponding job shop systems (Seifoddini \& Djassemi, 1995).

In a comparative study Seifoddini and Djassemi (1994) showed that QI more accurately predict the performance of a cellular manufacturing system than other measures such as grouping efficiency, grouping efficacy and grouping capability index. For this reason, QI is selected for the comparative study of the job shop and cellular manufacturing system in this study.

In the next section a procedure for the evaluation of the relative performances of a manufacturing system under job shop and cellular manufacturing subject to variations in reliability level will be 
presented. Also, the impact of reliability changes on the QI values which justify the development of cellular manufacturing system will be studied.

\subsection{Solution methodology}

As discussed earlier, reliability changes affect cellular manufacturing and job shop differently. As a result, while a manufacturing system with a certain QI level is suitable for conversion to cellular manufacturing at a particular reliability level, it may not lend itself to cellular manufacturing if the reliability drops to a lower level. To verify this premise, a simulation model for estimating the performance of a manufacturing system under job shop and cellular manufacturing under varying reliability levels is developed. The simulation model will be also used to calculate the QI values.

To incorporate reliability in the simulation model, a reliability function for individual machines is defined. For simplicity, it is assumed that the machine time to failure follows an exponential probability density function and is independent of the type of manufacturing system employed. The failure rate for a machine is determined based on the reliability value assigned to the machine over the time horizon, $t$ as follows. Let, the probability density function for failure be defined as

$$
f(t)=\lambda \mathrm{e}^{-\lambda t}, \quad t>0
$$

Then, the reliability function is

$$
R(t)=\mathrm{e}^{-\lambda t}
$$

If the reliability of a machine over time $t$ is assumed to be RT, then for the failure rated $\lambda$, we have

$$
\begin{aligned}
& \mathrm{RT}=\mathrm{e}^{-\lambda t} \\
& \ln \mathrm{RT}=-\lambda t \\
& \lambda=-\frac{\ln \mathrm{RT}}{t}
\end{aligned}
$$

the mean time between failure, MTBF is determined as

$$
\mathrm{MTBF}=\frac{1}{\lambda}
$$

In addition, it is assumed that repair begins immediately after the failure of a machine and repair time follows a uniform distribution.

A number of manufacturing situations represented by their machine-part matrices, production volume of parts, and processing times of manufacturing operations are used in the study. The simulation model determines the value of QI for each manufacturing situation. Then for each QI value, performance measures such as mean flow time and work-in-process (WIP) inventories are estimated under both cellular manufacturing and job shop for a given machine reliability level. The process is repeated for various QI values and different reliability levels. In this way, the change in the performance of a manufacturing system due to variations in reliability is evaluated. Furthermore, the intensity of these changes in cellular manufacturing and job shop and their impact on the QI levels for the development of cellular manufacturing systems are analyzed. 


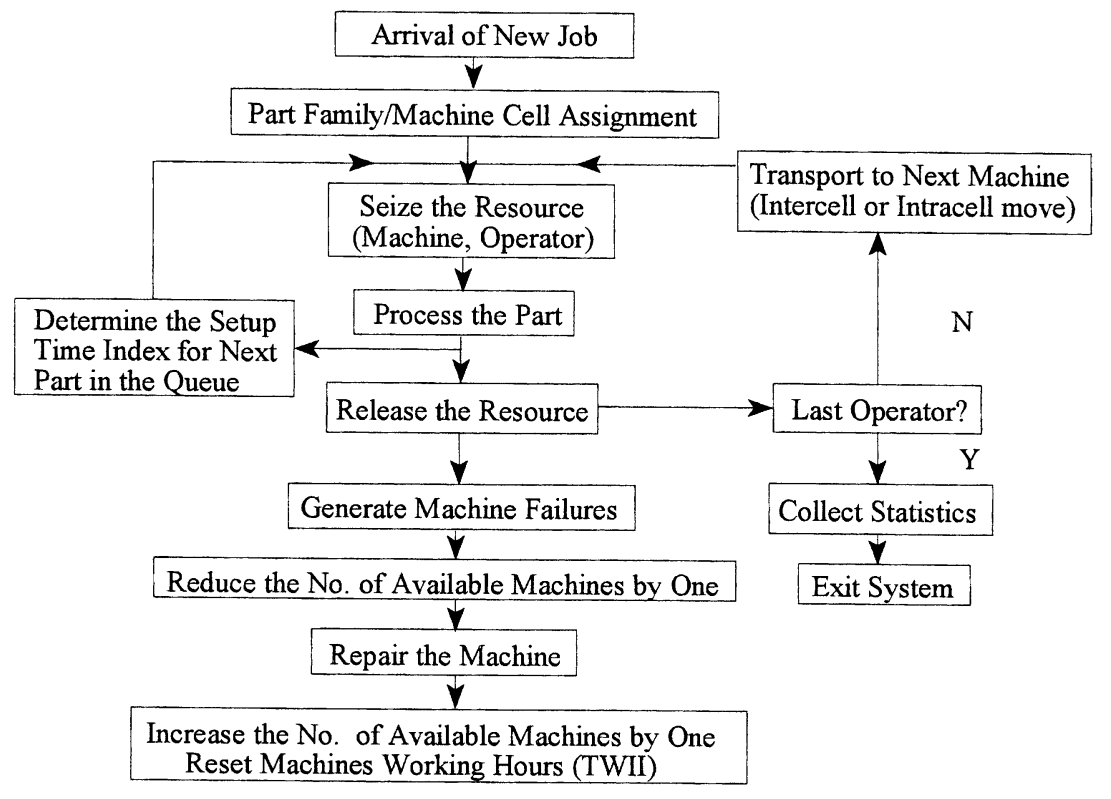

Fig. 3. Flow diagram of the simulation model including reliability submodel.

To determine the statistical significance of the difference between the performances of manufacturing systems under job shop and cellular manufacturing at difference reliability levels, a paired-t-test is employed. The following null hypotheses are tested.

No difference exists between mean flow times of the manufacturing system under job shop and cellular manufacturing at the given machine reliability level, RT.

No difference exists between WIP inventories of the manufacturing system under job shop and cellular manufacturing at the given machine reliability level, RT.

This experiment is intended to determine the relative sensitivity of job shop and cellular manufacturing to reliability changes.

The procedure in its algorithmic form can be presented as follows.

For each manufacturing system, convert its machine-part matrix into a block diagonal form using one of the machine-component grouping algorithms such as ROC (King \& Nachornchai, 1979), SCM. Use the simulation model to determine the QI value for the block diagonal form in step 1.

Estimate the mean flow time and WIP inventories under job shop and cellular manufacturing at the machine reliability of RT.

Test the statistical significance of the difference between mean flow times and WIP under job shop and cellular manufacturing using the paired-t-test.

Repeat steps 2 through 4 for a set of given machine-reliability levels.

Repeat steps 1 through 5 for a set of different QI values. 


\section{PARTS}

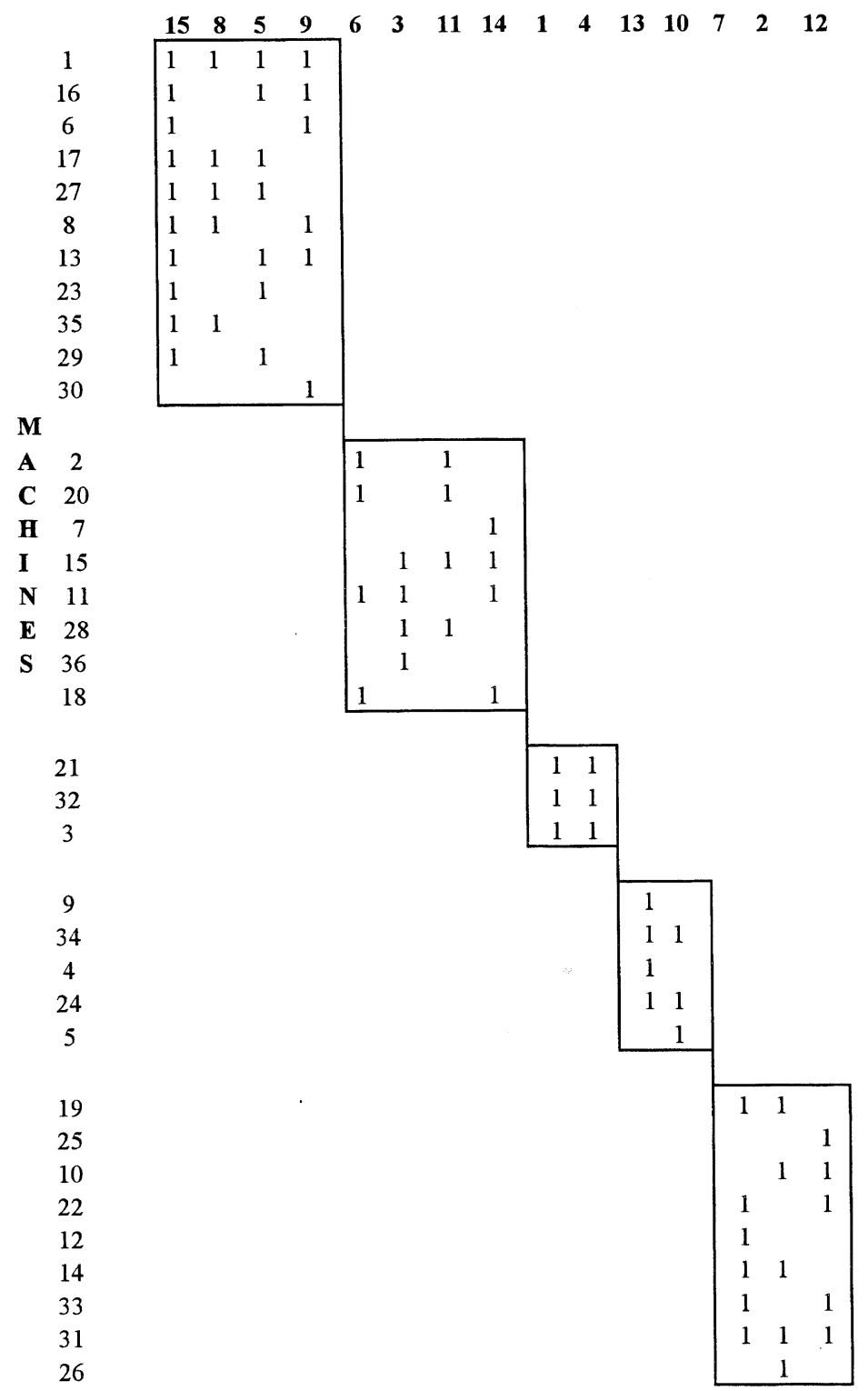

Fig. 4. The machine-part matrix of the manufacturing system with $\mathrm{QI}=1.0$. 
This procedure is a step forward toward the development of more realistic models for the evaluation of a manufacturing system for conversion to cellular manufacturing and will be demonstrated in the next section by a numerical example.

\subsection{Simulation model}

Two simulation models for job and cellular manufacturing shops were developed using SIMAN simulation language. Each model represents a hypothetical shop with 35 machines of ten different functional types, producing fifteen different part types. Demand is exponentially distributed with a mean of $60 \mathrm{~min}$. Upon order arrival, the type of each part is determined and the order is released to shop floor. In order to make a fair comparison analysis, the processing times and setup times for all operations are assumed to be deterministic. This eliminates any variation of processing times and setup times between two models. Setup times are sequence-dependent. That is, the setup time is a function of the degree of similarity between the next part to be processed and the part which is being processed. Part transfers between departments/cells have been modeled by using carts. The transfers within departments/cells are made by bins. The distance between machines and between departments/cell are determined using Micro-CRAFT (Tompkins \& Moor, 1980), a traditional facility layout planning software used frequently in literature. Machine breakdown is modeled based on its reliability. The reliability is estimated based on maintenance history file. Upon machine breakdown, the repair activity begins with the repair time uniformly distributed between 90 and $360 \mathrm{~min}$.

Fig. 3 depicts a general flow diagram of simulation model of cellular manufacturing shop. The reliability submodel controls the total machine working hours and generates machine breakdowns. For each reliability level, the model was run for 350 simulated days and data collected during the initial warmup period was discarded. Between 40-50 days (depending on the conditions of specific situations) of simulation results were discarded to minimize the effect of the transient period.

\section{Analysis of results}

A manufacturing system with 15 part types and 36 machines is used in this study. The first version of the machine-part matrix for this manufacturing system is given in Fig. 4. The demand for parts is assumed to be exponentially distributed with mean time between arrivals of $60 \mathrm{~min}$. The machine reliability is defined over a planning horizon of $100 \mathrm{~h}$. Reliability levels of 100, 90, 80 and $70 \%$ are considered. A $95 \%$ paired- $t$ confidence interval is constructed for the difference between mean flow times and WIPs under job shop and cellular manufacturing.

Table 1

Simulation results at $\mathrm{QI}=1.0$ for different reliability levels

\begin{tabular}{lllllrr}
\hline & Job shop & & CM & & \multicolumn{2}{c}{$\Delta$ and 95\% C.L. } \\
Reliability (\%) & Flow time & WIP & Flow time & WIP & \multicolumn{2}{c}{ Flow time } \\
100 & 84 & 3.2 & 66.4 & 2.1 & $16.8 \pm 1.2$ & $1.05 \pm .3$ \\
90 & 86 & 3.3 & 72 & 2.4 & $13.2 \pm 9$ & $1.02 \pm .1$ \\
80 & 89 & 3.4 & 77 & 2.7 & $10.5 \pm 1.1$ & $0.7 \pm .2$ \\
70 & 92 & 3.5 & 83 & 3.1 & $7.6 \pm .73$ & $0.35 \pm .1$ \\
\hline
\end{tabular}




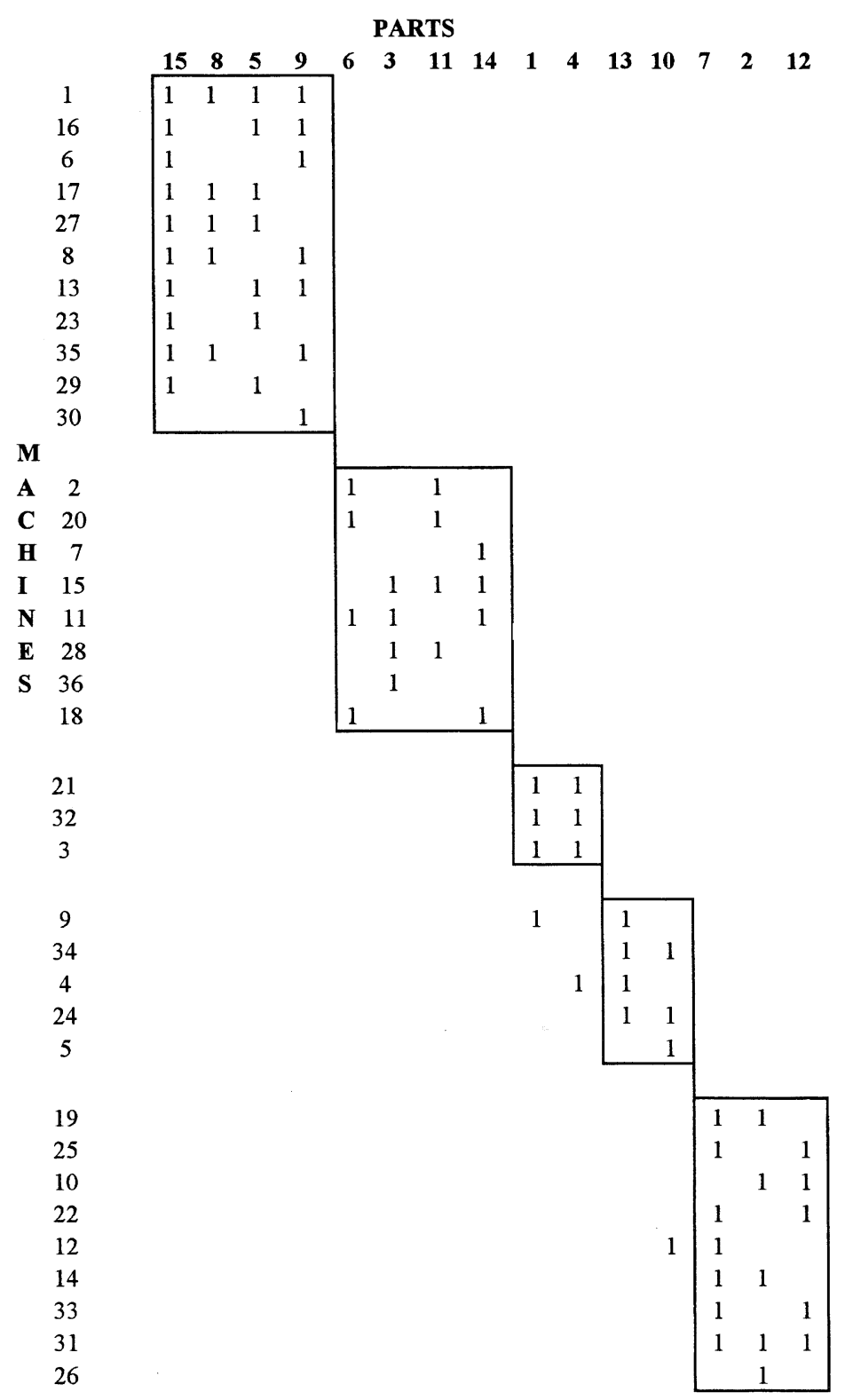

Fig. 5. Machine-part matrix QI $=0.85$.

The simulation results for QI value of one are summarized in Table 1. As the results indicate, the performance of the manufacturing system under both job shop and cellular manufacturing deteriorates as the machine reliability drops from 100 to $70 \%$. The more significant observation is the fact that the performance of the cellular manufacturing system is more severely affected than that of job shop system. This is evidenced by the decrease in the difference between mean flow time (from 16.8 to 7.6) and WIPs (from 1.05 to 0.35 ). According to these results the narrowing of the gap between the performances of the 
Table 2

Simulation results of $\mathrm{QI}=.85$ for different reliability levels

\begin{tabular}{|c|c|c|c|c|c|c|}
\hline & Job shop & & $\mathrm{CM}$ & & $\Delta$ and $95 \%$ & \\
\hline Reliability (\%) & Flow time & WIP & Flow time & WIP & Flow time & WIP \\
\hline 100 & 97.1 & 3.4 & 97.5 & 3 & $0.5 \pm .9$ & $0.4 \pm .05$ \\
\hline 90 & 101 & 2.9 & 104 & 3.3 & $3.1 \pm 1$ & $0.4 \pm .1$ \\
\hline 80 & 103 & 3.31 & 110 & 3.9 & $8 \pm 1.3$ & $0.5 \pm .3$ \\
\hline 70 & 109 & 3.4 & 119 & 4.5 & $11 \pm 1.6$ & $1.1 \pm .2$ \\
\hline
\end{tabular}

cellular manufacturing system and job shop system is due to faster deterioration of the performance of the cellular manufacturing system. Therefore, the simulation results verify the premise that at high QI values, cellular manufacturing systems outperform their corresponding job shop systems. The results also indicate that this superior performance is dependent on a high level of machine reliability. Therefore, in the decision making regarding the conversion from job shop to cellular manufacturing, the QI values of the machine-part matrix should be considered in conjunction with the machine reliability levels in order to make sound decisions.

The simulation results for the version of the manufacturing system with $\mathrm{QI}=0.85$ (the machine part matrix is given in Fig. 5) are summarized in Table 2. In this case, at $100 \%$ reliability level there is no statistically significant difference between the performance of the two types of systems. As the reliability drops from 100 to $70 \%$, the gap between the performances of the two systems widens, again, due to faster deterioration of the performance of the cellular manufacturing system. As in the previous case, the performance of cellular manufacturing systems is more sensitive to the machine reliability changes. This shows that at lower QI values, job shop may be a preferred manufacturing system, especially, if high machine reliability is not attainable.

The machine-part matrix for a version of the manufacturing system with QI $=0.75$ is given in Fig. 6 and the simulation results are given in Table 3. At this QI value, the job shop system outperforms the cellular manufacturing system even at $100 \%$ reliability level. As expected the difference between the performance of the two types of manufacturing systems becomes even greater as the machine reliability drops to lower levels. This indicates that at low QI values, the machine reliability is of secondary concern in the decision making regarding the conversion from job shop to cellular manufacturing.

This study provides more insight into two important areas in cellular manufacturing. First, findings in this paper support other studies that only at high QI values the conversion from job shop to cellular manufacturing is justified. Secondly, the study indicates that even at high threshold values of QI, the conversion to cellular manufacturing may not be beneficial if a high level of machine reliability can not be achieved. The study supports the idea that the performance of a cellular manufacturing system is more sensitive to machine reliability changes than the performance of a job shop system.

\section{Conclusions}

The relative performance of a manufacturing system under job shop and cellular manufacturing was evaluated at different QI values for a different number machine reliability levels. The simulation results show that while at high QI values, a cellular manufacturing system outperforms the corresponding job shop system, the results are highly dependent on machine reliability levels. Generally, the superiority of 


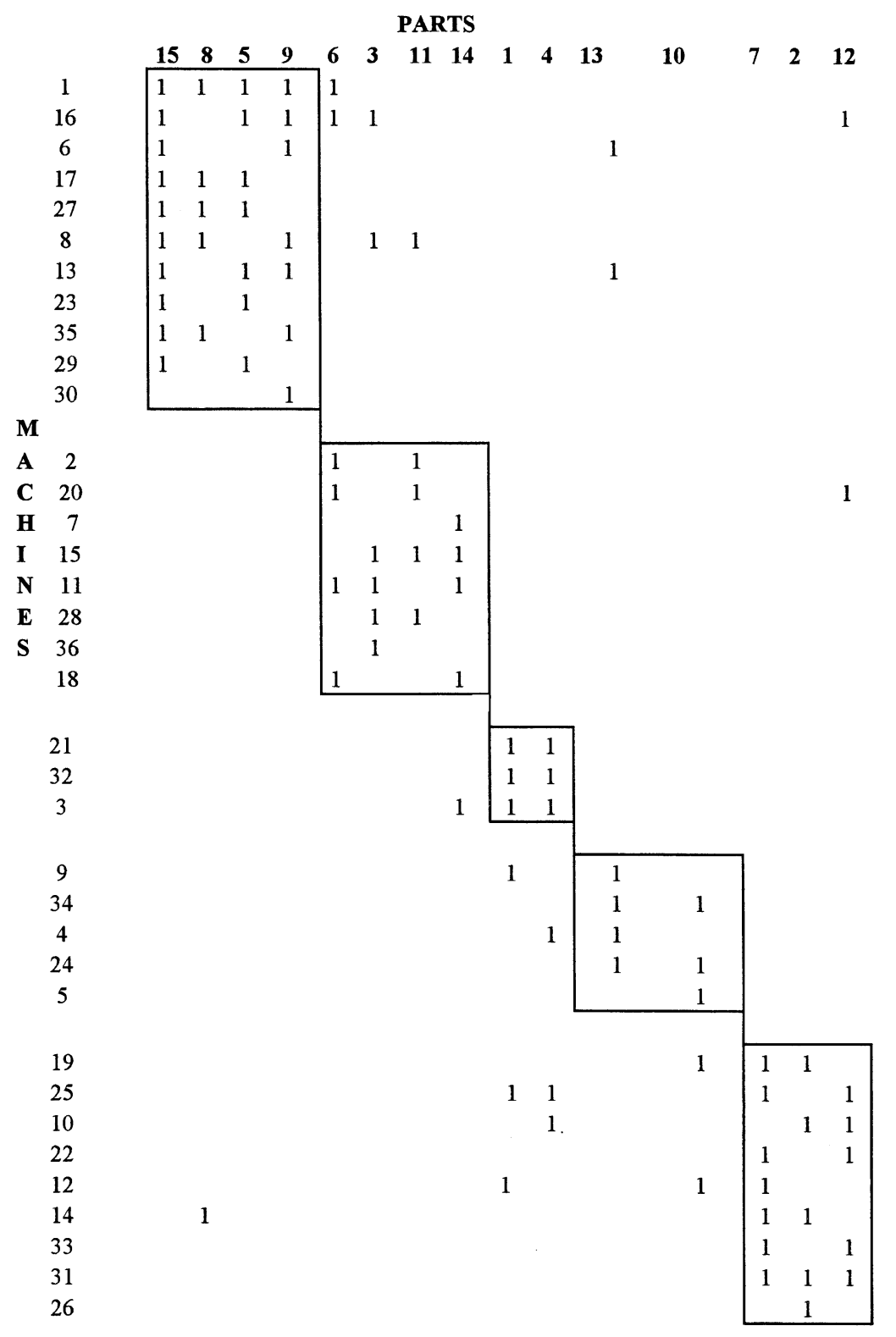

Fig. 6. Machine-part matrix $\mathrm{QI}=0.75$. 
Table 3

Simulation results at $\mathrm{QI}=0.75$ for different reliability levels

\begin{tabular}{|c|c|c|c|c|c|c|}
\hline & Job shop & & $\mathrm{CM}$ & & $\Delta$ and $95 \%$ C.I. & \\
\hline Reliability (\%) & Flow time & WIP & Flow time & WIP & Flow time & WIP \\
\hline 100 & 103 & 2.5 & 115 & 3.5 & $11.2 \pm 2.1$ & $0.7 \pm .65$ \\
\hline 90 & 105 & 2.8 & 118 & 3.9 & $13.2 \pm 1.3$ & $0.2 \pm .53$ \\
\hline 80 & 113 & 3.1 & 125 & 4.8 & $13.5 \pm 1.6$ & $1.5 \pm .3$ \\
\hline 70 & 116 & 3.5 & 133 & 5.4 & $16.5 \pm 1.1$ & $2.2 \pm .9$ \\
\hline
\end{tabular}

the cellular manufacturing system will rapidly disappear as the machine reliability deteriorates. The study supports the premise that the performance of cellular manufacturing systems is more sensitive to reliability changes than the performance of job shop systems.

\section{References}

Burbidge, J. (1992). Change to group technology: process organization is obsolete. International Journal of Production Research, 30 (5), 1209-1220.

Chandrasekharan, M. P., \& Rajagopalan, R. (1989). Groupability: an analysis of the properties of binary data matrices for group technology. International Journal of Production Research, 27 (6), 1035-1052.

Christy, P. D., \& Udayan, N. (1986). A simulation investigation of the design of group technology cells. Proceedings of Annual Meeting of Decision Sciences Institute (pp. 1201-1203).

Djassemi, M. (1994). The use of machine-grouping efficiency in comparison of job shop and cellular manufacturing systems: a simulation study. Unpublished PhD dissertation, Department of Industrial and Manufacturing Engineering, University of Wisconsin-Milwaukee.

Flynn, B. B., \& Jacobs, F. R. (1986). A simulation comparison of group technology with traditional job shop manufacturing. International Journal of Production Research, 24 (5), 1171-1192.

Flynn, B. B. (1989). Critical machines preventive maintenance policies for group technology shops. International Journal of Production Research, 27 (12), 2009-2020.

Hsu, C. P. (1990). Similarity coefficient approaches to machine-component cell formation in cellular manufacturing: a comparative study. Unpublished $\mathrm{PhD}$ thesis, Industrial and Systems Engineering, University of Wisconsin-Milwaukee, 1990.

Hyer, N. L. (1984). The potential of group technology for U.S. manufacturing. Journal of Operation Management, 4 (3), $183-201$.

King, J. R., \& Nakornchai, V. (1982). Machine-component group formation in group technology — review and extension, vol. 20, no. 2 (pp. 117-133).

Kapur, K. C., \& Lamberson, L. R. (1977). Reliability in engineering design, New York: Wiley.

Kumar, C. S., \& Chandrasekharan, M. P. (1990). Grouping efficacy: a quantitative orientation for goodness of block diagonal forms of binary matrices in group technology. International Journal of Production Research, 28 (2), $233-243$.

Law, A. M., \& Kelton, W. D. (1991). Simulation modeling and analysis. New York: McGraw-Hill.

Madu, C. S., \& Kuei, C. (1992). Simulation metamodels of system availability and optimum spare and repair units. Institute for Industrial Engineers (IIE) Transactions, 24 (5), 99-104.

McAuley, J. (1972). Machine grouping for efficient production. Production Engineering, 51, 53-57.

McCormick, W. T., Schweitzer, P. J., \& White, T. W. (1972). Problem decomposition and data reorganization by a clustering technique. Operations Research, 52, 993-1009.

Miriyala, K., \& Viswandham, N. (1989). Reliability analysis of flexible manufacturing systems. The International Journal of Flexible Manufacturing Systems, 2, 145-162. 
Seifoddini, H., \& Djassemi, M. (1995). Selection of machine-component charts for cellular manufacturing based on quality index. Proceedings of 1995 IEE Research Conference, Nashville, Tennessee.

Seifoddini, H., \& Djassemi, M. (1997). The threshold value of quality index for formation of cellular manufacturing systems. International. Journal of Production Research, 35.

Tompkins, J.A., Moor, M.J. (1980). Computer-aided layout: a user's guide. Publication No. 1. in the Monograph Series, Facilities Planning and Design Division, IIE Inc. 